\title{
An assessment of emergency department visits for cardiovascular diseases in the early phase of the COVID-19 pandemic in Istanbul
}

\author{
Yeşim Yasin ${ }^{1, *} \oplus$, Serpil Yaylacı ${ }^{2}$, Berna Eren ${ }^{3}$, Erdal Coşgun ${ }^{4}$
}

${ }^{1}$ Department of Public Health, Medical School, Acıbadem Mehmet Ali Aydınlar University, 34788 Istanbul, Turkey

${ }^{2}$ Department of Emergency Medicine, Medical School, Acıbadem Mehmet Ali Aydınlar University, 34788 İstanbul, Turkey

${ }^{3}$ Department of Health Management, Health Sciences Faculty, Acıbadem

Mehmet Ali Aydınlar University, 34788 Istanbul, Turkey

${ }^{4}$ Microsoft Genomics Team, AI \&

Research, Seattle, WA 98104, USA

\section{*Correspondence}

yesim.yasin@acibadem.edu.tr

(Yeşim Yasin)

\begin{abstract}
Objectives: The coronavirus disease (COVID-19) pandemic has had a severe impact with an excess of one hundred million cases and over two million deaths worldwide. Countries have adopted different paths toward 'flattening the curve'; however, many countries observed a common trend of people avoiding emergency departments (ED) for varying reasons. This study aims to investigate the ED utilization patterns of patients with cardiovascular diseases (CVD) in the early phases of COVID-19 in Istanbul, Turkey. Methods: The data were retrospectively collected in eight hospitals, which were authorized and declared as pandemic hospitals by the Turkish Ministry of Health. The data for these two particular periods of 1st March-30th June were compared between 2019 and 2020.

Results: A substantial and statistically significant decrease of $22.7 \%$ was observed in the total number of visits to EDs for cases of CVD from 534 cases in 2019 to 413 cases in 2020. ED visits showed statistically insignificant decreases of $11.6 \%$ for acute coronary syndrome/ACS) and 30.6\% for cerebrovascular events (CVE) between 2019 and 2020. Of the total 422 ACS cases, $67.8 \%$ were male and $32.2 \%$ were female; and of the 525 CVE cases, $50.3 \%$ were male and $49.7 \%$ were female. The median ages were 61 [6-97] for men and 69 [19-103] for women; the median ages were 59 [19-97] for patients with ACS and 68 [6-103] for patients with CVE. In 2020, the number of ACS cases showed a steady trend between March 1st and June 30th, followed by a prominent increase in June 2020. The monthly trends appeared to be very similar for CVE cases for 2019 and 2020. Of the 379 hospitalizations, $56.2 \%$ were diagnosed with ACS and $43.8 \%$ with CVE.

Conclusions: The findings suggest that patients tended to avoid timely medical care during the pandemic compared to pre-COVID-19. Stay-at-home orders and attempts to avoid contact with the virus may explain the dramatic decrease in the number of ED visits.
\end{abstract}

\section{Keywords}

COVID-19; Cardio-vascular diseases; Emergency department; Pandemic effects; Turkey 
capacity to accommodate surges in COVID-19 cases, the use of healthcare services for elective and emergency conditions was reported to decrease during this period [4]. Several studies showed that presentations to hospitals for acute conditions including myocardial infarction and stroke have decreased [5-8]. Additionally, Nourazari et al. [9] showed in their literature review study that Emergency Department (ED) visits decreased significantly during the COVID-19 pandemic and that a troubling proportion of this decrease was among patients who typically would have been admitted to the hospital. Similarly, Wongtanasarasin et al. [10] showed that the average number of daily ED visits decreased significantly in Thailand, where the national lockdown was associated with a significant reduction in average daily ED visits across traumatic and non-traumatic patients.

Turkey confirmed its first case of COVID-19 on 11 March 2020, the very same day that the World Health Organization (WHO) declared the novel coronavirus a pandemic. Subsequently, the Turkish government took stringent public health measures in response to the global health emergency. These measure were put in place to slow the spread of the SARS$\mathrm{CoV}-2$ virus in order to reduce the burden on the national healthcare system and thereby "flatten the curve". Among these public health measures exist the enforcement of a decree for hospitals meeting certain infrastructure criteria to be declared as "pandemic hospitals" regardless of their public or private status as of 20 March 2020. This was followed by enacting stay-at-home orders addressing certain age groups, including the announcement of a curfew for senior citizens (age 65 and older) as of 21st March and one for the people younger than the age of 20 as of 3rd April. 3rd April also marked the compulsory use of masks in public spaces, on transportation, and in all type of marketplaces [11]. Health authorities also introduced physical distancing measures to contain the spread of the virus and encouraged people to work from home. Beginning 11 April 2020, the government implemented 48hour lockdowns during the weekends in metropolitan cities, including Istanbul. These lockdowns lasted until the end of May and covered the national holidays in between these dates. Following the relative decrease in the number of new cases, the normalization process started 1 June 2020, relieving the curfew for certain social groups and re-opening social places.

Public policies and personal concerns alike deterred patients from seeking medical care even in emergencies. Subsequent to the ceasing of elective services and procedures in hospitals and imposing stay-at-home policies, emergency physicians began to report fewer patient visits to emergency departments. In this study, we aimed to investigate how the early phases of the COVID-19 pandemic influenced peoples' utilization patterns of emergency departments, specifically for cardiovascular diseases in Istanbul, Turkey.

\section{Materials and methods}

This retrospective study aimed to investigate how the recent COVID-19 pandemic, which has overwhelmed the health systems worldwide, has in its early phase affected visits regarding the potentially life-threatening cases of acute coronary syndrome (ACS) and cerebrovascular events (CVE; i.e., strokes) to the emergency departments in İstanbul, Turkey. İstanbul, as a transcontinental city, is located on both sides of the Bosphorus, with its commercial center in Europe and the remainder of the city in Asia. With a population of over 15 million residents, it is the largest city in Turkey and reflects the social and economic dynamics of the country as well as the health service provision. Whatever patterns observed in Istanbul regarding health service provisions during the pandemic can thus be generalized for the country.

ACS and CVE cases need emergency care the most due to their time-sensitive nature in terms of determining the necessary intervention. Considering this, the number of visits for these two groups of cases to emergency departments in eight private hospitals in Istanbul between 1st March and 30th June are compared between the years 2019 and 2020.

The hospitals included in this study belong to the same health group. These hospitals serve a wide range of populations and districts within Istanbul, as three of these hospitals are located on the Asian side and the other five are located on the European side of the city. All eight hospitals have emergency departments and were authorized and declared as pandemic hospitals by the Turkish Ministry of Health following its announcement of the first COVID-19 case in Turkey on 11 March 2020. In this study, the hospitals are coded with letters (from A to $\mathrm{H}$ ) in order to ensure data security.

This research received ethical approval from Acibadem University Medical Research Ethics Commission on 14 January 2021 (Decree No.2021-01/17). The data were retrospectively collected taking into consideration the significant dates during the course of the pandemic in Turkey, i.e., the announcement of the first case on 11 March 2020 and the start of the normalization process on 1 June 2020. Therefore, the data cover a total of 947 visits to the emergency departments of the above-mentioned hospitals for cases of ACS and CVE, as diagnosed by the emergency physicians with the appropriate ICD-10 codes, between 1 March-30 June 2019 and 1 March30 June 2020.

The data includes the cases that are classified by emergency physicians with the following ICD-10 codes: Acute Coronary Syndrome (I20, I21, I22, I24); Cerebrovascular Events [nonhemorrhagic strokes (G45, G46, I63, I64, I65) and hemorrhagic strokes (I60, I61, I62)].

Descriptive statistics of the numeric variable (age) was expressed as mean, standard deviation, median, and max-min values. Categorical parameters were represented with frequency and percentage values. The Kolmogorov-Smirnov test was used to test whether the data represented normal distribution. The Chi-Square test and Kruskal Wallis test were used for standard statistical analyses. Dunn's test was used for multiple comparisons for multi-class variables. Fisher's exact chi-square test was used for categorical data, which had a low frequency on the Fisher cross-table. We have represented the time dependent variables' longitudinal trend with line charts and classical bar charts for categorical variables. $p$ value less than 0.05 was considered to be statistically significant. $\mathrm{R}$ programming language (Version 4.0.3) was used for all statistical analysis. 


\section{Findings}

The study included a total of 947 unique visits, specifically for ACS and CVE related diagnoses, to the emergency departments of eight hospitals from 1 March 2019-30 June 2019 and 1 March 2020-30 June 2020.

In 2019, there were 534 (56.4\% of patients across these two periods) ED visits compared to only 413 (43.6\% of patients across these two periods) ED visits in 2020; thus the number of ED visits significantly decreased by $22.7 \%$ from 2019 to $2020(p<0.05)$.

In 2019, $224(41.9 \%)$ of the 534 unique ED visits were diagnosed with ACS and 310 (58.1\%) were diagnosed with CVE. In 2020, of the 413 visits, the numbers were 198 (47.9\%) and $215(52.1 \%)$ for ACS and CVE, respectively. The number of ED visits for ACS showed a decrease of $8.8 \%$, and the number of visits for CVE showed a decrease of $30.6 \%$ from 2019 to 2020 .

Taking into consideration that 11 March 2020 (announcement of first case in Turkey) and 1 June 2020 (lifting of all public health measures) are the prominent dates in the timeline of COVID-19 pandemic in Turkey, data were also separately analyzed to reveal these critical dates. During the period between 11 March-31 May, the total number of ED visits were 366 in 2019 and 253 in 2020, showing a decrease of $30.9 \%$ between 2019 and 2020. For this period, there were 147 ACS-related ED visits in 2019 and 117 ED visits in 2020, showing a decrease of $20.4 \%$ between 2019 and 2020 . There were 219 CVE-related ED visits in 2019, and 136 ED visits in 2020, showing a decrease of $37.9 \%$ between 2019 and 2020. However, these decreases in ED visits from 2019 to 2020 did not reach statistical significance $(p>0.05)$.

Of the total 947 unique ED visits included in this study over the two periods, $550(58.1 \%)$ were male and $397(41.9 \%)$ were female. In $2019,311(58.2 \%)$ of the total $534 \mathrm{ED}$ visits were male and $223(41.8 \%)$ were female; and in 2020, 239 $(57.9 \%)$ of the total $413 \mathrm{ED}$ visits were male and $174(42.1 \%)$ were female. The gender distribution of ED visits showed no statistically significant difference between 2019 and $2020(p>$ $0.05)$. The male to female ratio was very similar in 2019 and 2020 , i.e., 1.39 and 1.37 respectively. Between 2019 and 2020, the number of ED visits showed a decrease of $23.2 \%$ for men and $22.0 \%$ decrease for women. However, when detailed for the lockdown period, the ratios were 1.57 in 2019 and 1.48 in 2020. The number of ED visits for this specific period showed a decrease of $32.6 \%$ for men and $28.2 \%$ decrease for women between 2019 and 2020. The gender distribution of ED visits when detailed with the significant dates regarding the lockdown and the normalization period also showed no significant difference between 2019 and 2020 ( $p>0.05$ ).

A total of $74.7 \%$ (707) of the ED visits were received by four hospitals, three of which were located on the European side of Istanbul. The distribution of the $947 \mathrm{ED}$ visits across the hospitals included in this study showed a statistically significant difference between 2019 and $2020(p<0.05)$ (Tables 1,2).

The dataset contained $422(44.6 \%)$ ACS and 525 (55.4\%) CVE diagnoses in total. In 2019, 224 (41.9\%) of the total 534 ED visits were diagnosed with ACS, and 310 (58.1\%) were diagnosed with CVE. In 2020, within the total 413 ED visits, the numbers were 198 (47.9\%) and $215(52.1 \%)$, respectively, showing a decrease of $11.6 \%$ for ACS and $30.6 \%$ for CVE between 2019 and 2020. The distribution of diagnoses showed no statistically significant difference between 2019 and 2020 $(p>0.05)$.

When detailed particularly for the lockdown period, i.e., 11 March-31 May, the number of ED visits for ACS cases showed a decrease of $20.4 \%$ from 147 cases in 2019 to 117 in 2020; and the number of ED visits for CVE cases showed a decrease of $37.9 \%$ from 219 cases to 136 in 2020 . The distribution of ED visits by diagnosis during the lockdown period showed no statistically significant difference between 2019 and 2020 (Fig. 1).

In 2019, the number of ACS cases showed a steady horizontal trend between 1 March and 30 June; however, in 2020, the steady course between March and May was followed by a prominent increase in June. As for CVE cases, the monthly trends for 2019 and 2020 appeared to be very similar. The monthly distribution of ED visits by diagnosis between 2019 and 2020 showed statistically significant difference $(p<0.05)$ (Fig. 2).

Of the total 422 ACS cases, 286 (67.8\%) were male and 136 (32.2\%) were female; and of the $525 \mathrm{CVE}$ cases, 264 (50.3\%) were male and $261(49.7 \%)$ were female. The distribution of diagnoses by gender showed statistically significant difference $(p<0.05)$ (Table 3).

The mean age was $61.3 \pm 16.2$ for men and $66.2 \pm 16.9$ for women; and the medians were 61 [6-97] and 69 [19103], respectively. The medians showed a statistically significant difference between men and women $(p=0.001<$ 0.05 ) (Table 4$)$. The mean and median age showed statistically significant differences between hospitals $(p<0.05)$.

Within the total $947 \mathrm{ED}$ visits, the mean age was $60.3 \pm$ 15.6 for ACS and $65.9 \pm 17.1$ for CVE; and the medians were 59 [19-97] and 68 [6-103], respectively. The age medians showed statistically significant difference between ACS and CVE diagnoses $(p<0.05)$ (Table 5).

Of the total $947 \mathrm{ED}$ visits, 379 (40.2\%) were admitted to the hospital. The distribution of admissions showed statistically significant difference between the eight hospitals $(p<0.05)$ (Table 6).

Of the 379 hospitalizations, 213 (56.2\%) were diagnosed with ACS, and 166 (43.8\%) were diagnosed with CVE. The distribution of admissions by diagnosis showed a statistically significant difference $(p<0.05)$ (Table 7).

Of the $413 \mathrm{ED}$ visits in 2020, a total of $30(7.3 \%)$ cases in five hospitals were provisionally diagnosed with COVID-19. Of these, $19(63.3 \%)$ patients were female and the majority (46.7\%) of the patients were admitted in April 2020.

Of the total 379 hospital admissions, $51(13.5 \%)$ resulted in death. $27(52.9 \%)$ of these deaths were male patients and 24 (47.1\%) were female patients. A total of 24 (47.1\%) deaths occurred in 2019 and 27 (52.9\%) deaths occurred in 2020 . Only 3 deaths in 2020 were pre-diagnosed with COVID-19.

\section{Discussion}

This study aimed to present a retrospective snapshot of the emergency departments in Turkey and to estimate the impact 
TA B L E 1. The distribution of emergency department visits across hospitals in 2019 and 2020.

\begin{tabular}{|c|c|c|c|c|c|c|c|c|c|c|}
\hline \multicolumn{11}{|c|}{ Hospitals } \\
\hline Years & & A & $\mathrm{B}$ & $\mathrm{C}$ & $\mathrm{D}$ & $\mathrm{E}$ & $\mathrm{F}$ & $\mathrm{G}$ & $\mathrm{H}$ & Total \\
\hline \multirow{6}{*}{2019} & \multirow{2}{*}{ 1-10 March } & 3 & 6 & 5 & 7 & 0 & 9 & 16 & 1 & 47 \\
\hline & & $6.40 \%$ & $12.80 \%$ & $10.60 \%$ & $14.90 \%$ & $0.00 \%$ & $19.10 \%$ & $34.00 \%$ & $2.10 \%$ & $100.00 \%$ \\
\hline & \multirow{2}{*}{11 March-31 May } & 46 & 89 & 38 & 41 & 15 & 39 & 87 & 11 & 366 \\
\hline & & $12.60 \%$ & $24.30 \%$ & $10.40 \%$ & $11.20 \%$ & $4.10 \%$ & $10.70 \%$ & $23.80 \%$ & $3.00 \%$ & $100.00 \%$ \\
\hline & \multirow{2}{*}{ 1-30 June } & 13 & 27 & 15 & 13 & 2 & 12 & 37 & 2 & 121 \\
\hline & & $10.70 \%$ & $22.30 \%$ & $12.40 \%$ & $10.70 \%$ & $1.70 \%$ & $9.90 \%$ & $30.60 \%$ & $1.70 \%$ & $100.00 \%$ \\
\hline & Total & 62 & 122 & 58 & 61 & 17 & 60 & 140 & 14 & 534 \\
\hline \multirow{7}{*}{2020} & \multirow{2}{*}{ 1-10 March } & 7 & 19 & 2 & 9 & 0 & 5 & 10 & 1 & 53 \\
\hline & & $13.20 \%$ & $35.80 \%$ & $3.80 \%$ & $17.00 \%$ & $0.00 \%$ & $9.40 \%$ & $18.90 \%$ & $1.90 \%$ & $100.00 \%$ \\
\hline & \multirow{2}{*}{11 March-31 May } & 56 & 54 & 13 & 23 & 11 & 11 & 67 & 18 & 253 \\
\hline & & $22.10 \%$ & $21.30 \%$ & $5.10 \%$ & $9.10 \%$ & $4.30 \%$ & $4.30 \%$ & $26.50 \%$ & $7.10 \%$ & $100.00 \%$ \\
\hline & \multirow{2}{*}{ 1-30 June } & 14 & 24 & 6 & 14 & 7 & 9 & 25 & 8 & 107 \\
\hline & & $13.10 \%$ & $22.40 \%$ & $5.60 \%$ & $13.10 \%$ & $6.50 \%$ & $8.40 \%$ & $23.40 \%$ & $7.50 \%$ & $100.00 \%$ \\
\hline & Total & 77 & 97 & 21 & 46 & 18 & 25 & 102 & 27 & 413 \\
\hline
\end{tabular}

TA B L E 2. The distribution of emergency department visits by diagnoses in 2019 and 2020.

\begin{tabular}{|c|c|c|c|c|c|c|}
\hline & & & \multicolumn{2}{|c|}{ ICD } & \multirow[t]{2}{*}{ Total } & \multirow[t]{2}{*}{ Statistics } \\
\hline & & & ACS & CVE & & \\
\hline & \multirow{4}{*}{2019} & Count & 224 & 310 & 534 & \\
\hline & & $\%$ within years & $41.9 \%$ & $58.1 \%$ & $100.0 \%$ & \\
\hline \multirow{4}{*}{ Years } & & $\%$ within ICD & $53.1 \%$ & $59.0 \%$ & $56.4 \%$ & \\
\hline & & Count & 198 & 215 & 413 & \\
\hline & \multirow{2}{*}{2020} & $\%$ within Years & $47.9 \%$ & $52.1 \%$ & $100.0 \%$ & Chi-Square $=3.387 p=0.066$ \\
\hline & & $\%$ within ICD & $46.9 \%$ & $41.0 \%$ & $43.6 \%$ & \\
\hline \multirow[t]{3}{*}{ Total } & & Count & 422 & 525 & 947 & \\
\hline & & $\%$ within Years & $44.6 \%$ & $55.4 \%$ & $100.0 \%$ & \\
\hline & & $\%$ within ICD & $100.0 \%$ & $100.0 \%$ & $100.0 \%$ & \\
\hline
\end{tabular}

TA B L E 3. The distribution of diagnoses by gender.

\begin{tabular}{|c|c|c|c|c|c|c|}
\hline & & & \multicolumn{2}{|c|}{ ICD } & \multirow[t]{2}{*}{ Total } & \multirow[t]{2}{*}{ Statistics } \\
\hline & & & $\mathrm{ACS}$ & CVE & & \\
\hline \multirow{6}{*}{ Gender } & \multirow{4}{*}{ Men } & Count & 286 & 264 & 550 & \\
\hline & & $\%$ within Gender & $52.0 \%$ & $48.0 \%$ & $100.0 \%$ & \\
\hline & & $\%$ within ICD & $67.8 \%$ & $50.3 \%$ & $58.1 \%$ & \\
\hline & & Count & 136 & 261 & 397 & \\
\hline & \multirow[t]{5}{*}{ Women } & $\%$ within Gender & $34.3 \%$ & $65.7 \%$ & $100.0 \%$ & Chi-Square $=29.383 p<0.001$ \\
\hline & & $\%$ within ICD & $32.2 \%$ & $49.7 \%$ & $41.9 \%$ & \\
\hline \multirow{3}{*}{ Total } & & Count & 422 & 525 & 947 & \\
\hline & & $\%$ within Gender & $44.6 \%$ & $55.4 \%$ & $100.0 \%$ & \\
\hline & & $\%$ within ICD & $100.0 \%$ & $100.0 \%$ & $100.0 \%$ & \\
\hline
\end{tabular}

of the COVID-19 pandemic. This was done by characterizing the patients, visits, and diagnoses over the specific example of individual visits to EDs in Istanbul for CVDs in the early phase of the pandemic.

The findings of the study revealed a substantial and statistically significant decrease of $22.7 \%$ in the total number of visits 


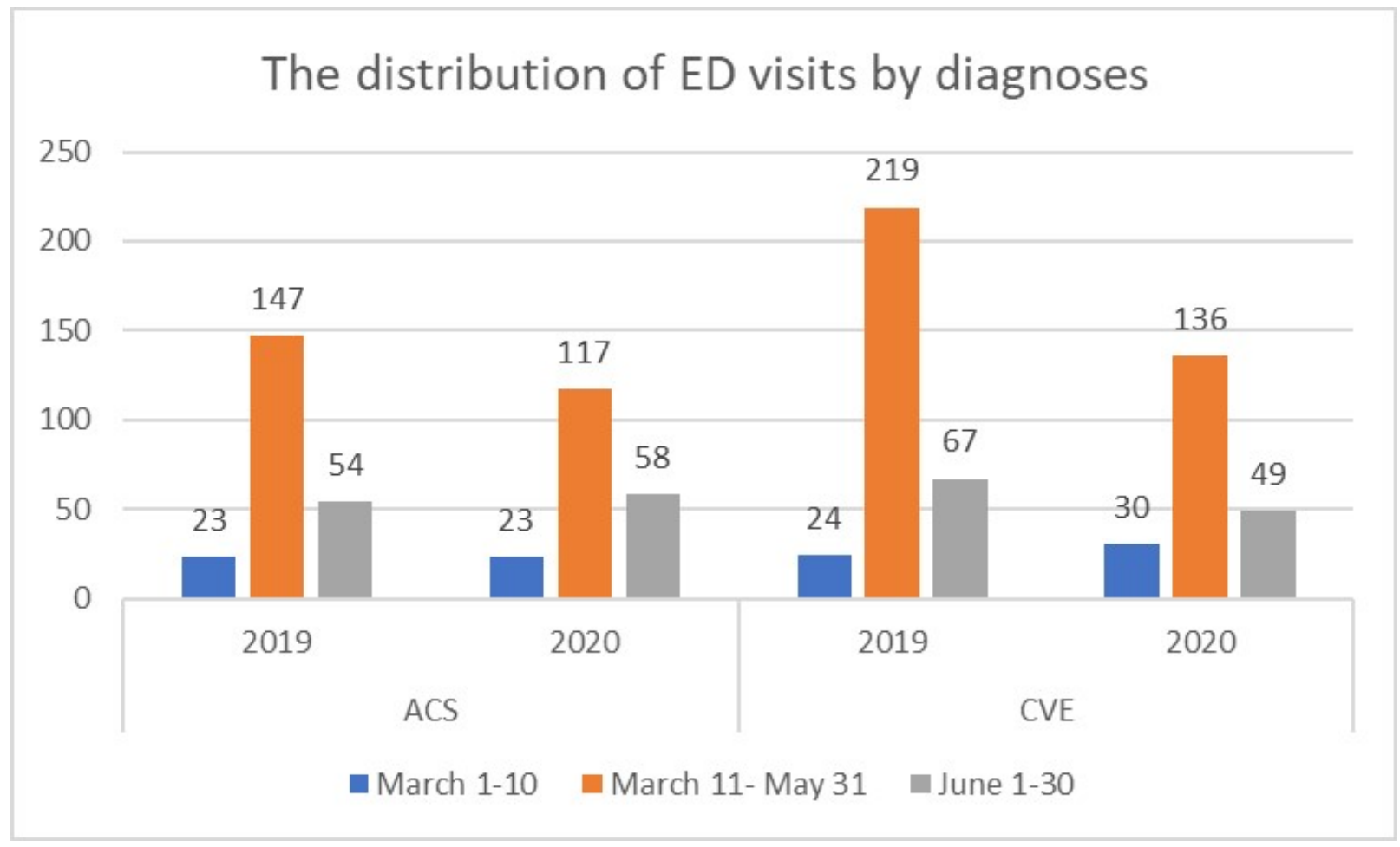

F I G U R E 1. The distribution of emergency department visits by diagnoses in 2019 and 2020.

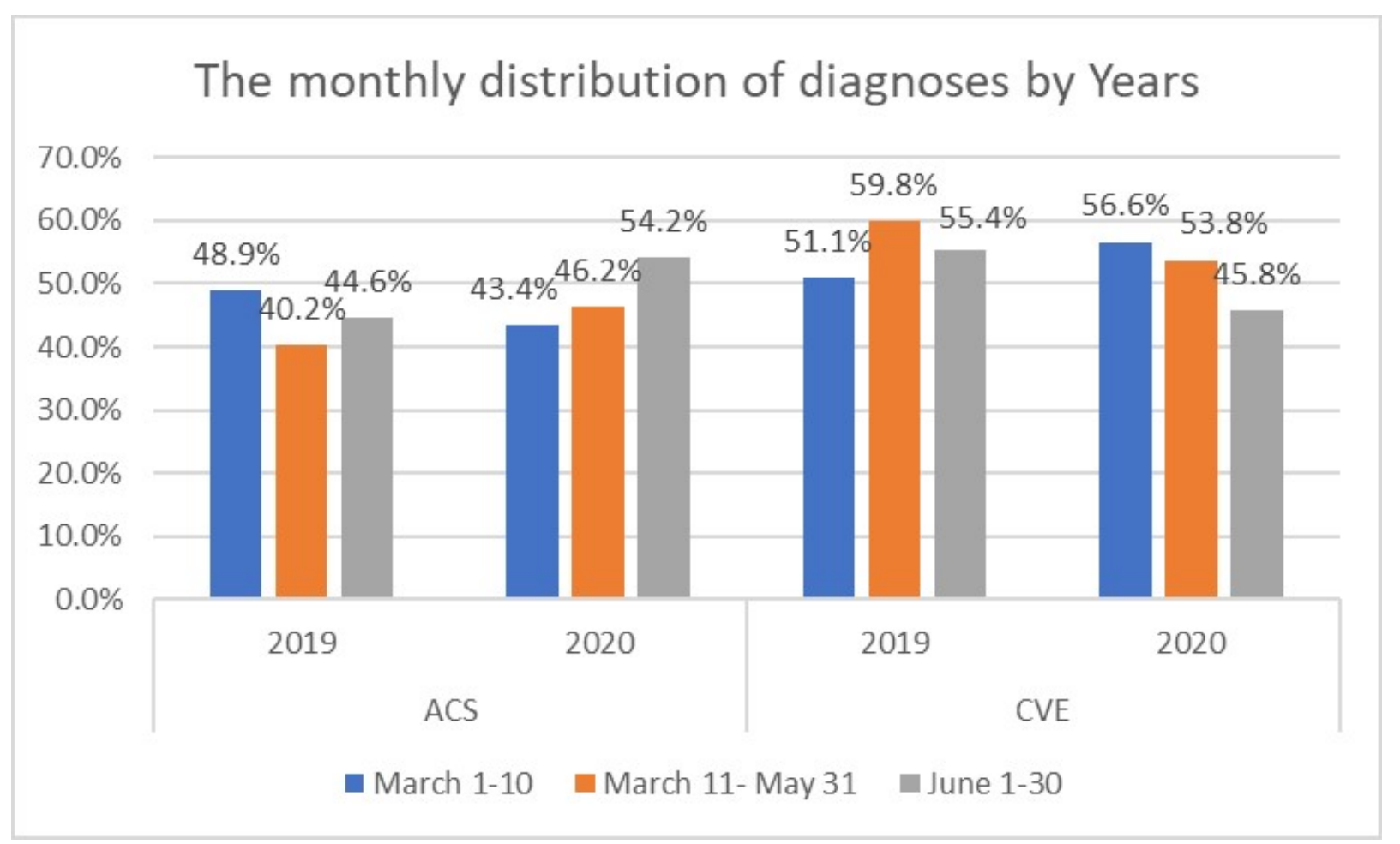

F I G U RE 2. The monthly distribution of emergency department visits by diagnoses in 2019 and 2020.

TA B L E 4. The distribution of mean and median age by gender.

\begin{tabular}{|c|c|c|c|c|}
\hline & Gender & $\mathrm{X}^{-} \pm \mathrm{SS}$ & $\tilde{X}[\min -\max ]$ & $p$ value \\
\hline \multirow{2}{*}{ Age } & Men & $61.3 \pm 16.2$ & 61 [6-97] & \multirow{2}{*}{$p<0.001$} \\
\hline & Women & $66.2 \pm 16.9$ & 69 [19-103] & \\
\hline
\end{tabular}

TA B L E 5. The distribution of mean and median age by diagnoses.

$\begin{array}{ccccl} & \text { ICD } & \mathrm{X}^{-} \pm \mathrm{SS} & \tilde{\mathrm{X}}[\min -\max ] & p \text { value } \\ \text { Age } & \text { ACS } & 60.3 \pm 15.6 & 59[19-97] & \\ & \text { CVE } & 65.9 \pm 17.1 & 68[6-103] & p<0.001\end{array}$


TA B L E 6. The distribution of admissions across hospitals.

\begin{tabular}{|c|c|c|c|c|c|c|}
\hline & & & Hospital & n/Hospitalization & Total & Statistics \\
\hline & & & No & Yes & & \\
\hline & & Count & 60 & 79 & 139 & \\
\hline & A & $\%$ within & $43.2 \%$ & $56.8 \%$ & $100.0 \%$ & \\
\hline & & $\%$ within & $10.6 \%$ & $20.8 \%$ & $14.7 \%$ & \\
\hline & & Count & 134 & 85 & 219 & \\
\hline & $\mathrm{B}$ & \% within Hospitals & $61.2 \%$ & $38.8 \%$ & $100.0 \%$ & \\
\hline & & $\%$ within Admission & $23.6 \%$ & $22.4 \%$ & $23.2 \%$ & \\
\hline & & Count & 44 & 35 & 79 & \\
\hline & $\mathrm{C}$ & \% within Hospitals & $55.6 \%$ & $44.4 \%$ & $100.0 \%$ & \\
\hline & & $\%$ within Admission & $7.7 \%$ & $9.2 \%$ & $8.2 \%$ & \\
\hline & & Count & 59 & 48 & 107 & \\
\hline & $\mathrm{D}$ & $\%$ within Hospitals & $55.1 \%$ & $44.9 \%$ & $100.0 \%$ & \\
\hline Hosnitols & & $\%$ within Admission & $10.4 \%$ & $12.7 \%$ & $11.2 \%$ & \\
\hline 100 sitais & & Count & 24 & 11 & 35 & \\
\hline & $\mathrm{E}$ & $\%$ within Hospitals & $68.6 \%$ & $31.4 \%$ & $100.0 \%$ & Chi-Square $=45.500 p<0.001$ \\
\hline & & $\%$ within Admission & $4.2 \%$ & $2.9 \%$ & $3.7 \%$ & \\
\hline & & Count & 66 & 19 & 85 & \\
\hline & $\mathrm{F}$ & $\%$ within Hospitals & $77.6 \%$ & $22.4 \%$ & $100.0 \%$ & \\
\hline & & $\%$ within Admission & $11.6 \%$ & $5.0 \%$ & $8.9 \%$ & \\
\hline & & Count & 145 & 97 & 242 & \\
\hline & G & $\%$ within Hospitals & $59.9 \%$ & $40.1 \%$ & $100.0 \%$ & \\
\hline & & $\%$ within Admission & $25.7 \%$ & $25.6 \%$ & $25.7 \%$ & \\
\hline & & Count & 36 & 5 & 41 & \\
\hline & $\mathrm{H}$ & $\%$ within Hospitals & $87.8 \%$ & $12.2 \%$ & $100.0 \%$ & \\
\hline & & $\%$ within Admission & $6.3 \%$ & $1.3 \%$ & $4.3 \%$ & \\
\hline & & Count & 568 & 379 & 947 & \\
\hline Total & & $\%$ within Hospitals & $60.0 \%$ & $40.0 \%$ & $100.0 \%$ & \\
\hline & & $\%$ within Admission & $100.0 \%$ & $100.0 \%$ & $100.0 \%$ & \\
\hline
\end{tabular}

TA B L E 7. The distribution of admissions by diagnoses.

\begin{tabular}{|c|c|c|c|c|c|c|}
\hline & & & \multicolumn{2}{|c|}{ Hospital Admission/Hospitalization } & \multirow[t]{2}{*}{ Total } & \multirow[t]{2}{*}{ Statistics } \\
\hline & & & No & Yes & & \\
\hline \multirow{6}{*}{ ICD } & \multirow{4}{*}{ ACS } & Count & 209 & 213 & 422 & \\
\hline & & $\%$ within ICD & $49.5 \%$ & $50.5 \%$ & $100.0 \%$ & \\
\hline & & $\%$ within Admission & $36.7 \%$ & $56.2 \%$ & $44.5 \%$ & \\
\hline & & Count & 359 & 166 & 525 & \\
\hline & \multirow[t]{3}{*}{ CVE } & $\%$ within ICD & $68.4 \%$ & $31.6 \%$ & $100.0 \%$ & Chi-Square $=34.687 p<0.001$ \\
\hline & & $\%$ within Admission & $63.3 \%$ & $43.8 \%$ & $55.5 \%$ & \\
\hline \multirow{3}{*}{\multicolumn{2}{|c|}{ Total }} & Count & 568 & 379 & 947 & \\
\hline & & $\%$ within ICD & $59.8 \%$ & $40.2 \%$ & $100.0 \%$ & \\
\hline & & $\%$ within Admission & $100.0 \%$ & $100.0 \%$ & $100.0 \%$ & \\
\hline
\end{tabular}

to EDs for CVDs between March-July of 2019 and MarchJuly of 2020. Although the number of ED visits showed a decrease of $11.6 \%$ for ACS and 30.6\% for CVE between 2019 and 2020, these differences were not statistically significant. Interestingly, while the number of CVE cases had a relatively horizontal monthly trend in both 2019 and 2020, the number 
of ACS cases showed a prominent increase in June 2020. The number of ED visits showed no significant difference by gender or age.

From a public health point of view, our findings suggest that patients with life threatening conditions are inclined to defer seeking timely medical care and to underutilize the emergency services compared to before the COVID-19 pandemic. Fear of the hospital environment in order to avoid contracting the virus and overall reduced physical activity due to stay-athome orders may explain the dramatic decrease in the number of CVD-related ED visits. This reduction is likely to have been a direct consequence of the physical distancing measures implemented on a national scale. This represents the effects of the major service reconfiguration that disbanded the elective, private, and inpatient practice to cater to the increased space required to host acute COVID patients.

The COVID-19 pandemic has had serious consequences on emergency care on a global scale. Amid the pandemic, several publications have documented anecdotal reports of a general drop in emergency department volumes and a substantial decrease in the number of patients presenting to hospitals with non-COVID-19 emergent diseases, including ischemic stroke and myocardial infarction in the US, Spain, and Australia [6, 10, 12-17]. This strong global reduction in the usual emergency department activities and the shift from a systematic recognition of potential cases to the one of epidemic mitigation, defined as the "COVID paradox", required the implementation of crisis management measures within hospital emergency medicine services, transforming emergency departments to disaster departments to respond to the COVID19 pandemic [18].

In the United Kingdom (UK), the total attendances at EDs decreased by $29.4 \%$ in March 2020 compared to the same month in 2019, and the number of people attending EDs with a heart attack dropped by half between the beginning and end of March [3]. The study by Mafham et al. [19] showed that the average weekly number of ACS admissions started to decline at least 2 weeks before the first UK death from COVID-19 (5 March 2020) and about a month before the UK Government implemented the lockdown (23 March 2020). By the end of March 2020, there was a decrease of $40 \%$ in ACS admission compared with the average weekly number observed during 2019.

De Rosa et al. [20] observed a 48.4\% reduction in admissions to Italian cardiac care units for acute myocardial infarction during a one-week period during the COVID-19 outbreak, compared with the equivalent week in 2019, stating that this reduction across Italy was associated with a parallel increase in fatality and complication rates.

Baum et al. [8] showed that presentations to VA (Veterans Affairs) inpatient facilities in the US for myocardial infarction and stroke have decreased by $40.3 \%$ and $51.9 \%$, between weeks $5-10$ and $11-16$ of 2020, representing pre-COVID-19 and post-COVID-19 periods, respectively.

Similar to our study, Bhambhvani et al. [21] extracted diagnoses of acute MI with ICD-10 code I21, ischemic stroke with I63, and non-traumatic subarachnoid hemorrhage with I60 at two academic medical centers in the US for the period between 1 March 2018 and 22 May 2020. They found significant drops in the daily caseload of those medical emergencies following the onset of the COVID-19 pandemic.

Daoulah et al. [22] retrospectively identified all STelevation myocardial infarction (STEMI) cases from 16 centers in Saudi Arabia between 1 January and 30 April 2020. When compared to the same period in 2018 and 2019, there was a reduction of $28 \%$ in total STEMI volumes during the pandemic; and data reflected that although the standard of care for STEMI patients had continued during the COVID-19 pandemic, patients had delayed presenting to hospitals.

Not all research showed a reduction in the number of ED visits for CVDs. A retrospective cohort study was conducted by Kuitunen et al. [23] at three large EDs covering $1 / 6$ of the population of Finland, where the COVID-19 outbreak had led to a nationwide lockdown on 16 March 2020. This study revealed that while there was a major decrease in the rate of ED visits due to back or limb pain and (not so surprisingly) in infectious diseases, the rates of acute myocardial infarctions and cerebral strokes remained stable. It could be argued that the observed differences between countries might have depended on their resources, healthcare system organizations, and access or use of health services as they faced the pandemic at diverse time points and with different approaches.

The globally observed reduction in the number of ED visits also raises the concern that some patients may have died from an acute cardiovascular event without seeking medical attention. Griffin stated that deaths resulting from COVID19 account for only half of the excess number of at-home deaths during the pandemic [24]. Additionally, Wu et al. [25] found that the COVID-19 pandemic resulted in an inflation in acute cardiovascular deaths in England and Wales; and almost half of these deaths had occurred in the community, either at home or care homes and hospices, most being non-COVID19-related. The combination of fewer patients presenting with medical emergencies and an increased number of non-COVID19-related at-home deaths might be the result of patients' fear of exposure to COVID-19, which might have led individuals to defer care for acute conditions [21].

\section{Conclusions}

We found a substantial decrease in the number of ED visits for the diagnoses of ACS and CVE during the first lockdown period in Istanbul. The causes for this decrease are likely multifactorial and include patient avoidance of emergency care for fear of COVID-19. These changes in patient presentation patterns may reflect the following: concerns of contracting COVID-19 in healthcare settings; concerns of overburdening the healthcare system with unrelated conditions; adhering to public health recommendations; increased thresholds for hospitalization by clinicians; and changes in patient lifestyle and self-management in the context of social distancing. The implications of the decreases in hospitalizations for chronic diseases are concerning for the possibility that sick patients are not obtaining the necessary medical care. While hospitalizations for acute events began recovering in the late COVID-19 period, many of those related to chronic diseases generally did not. This reduction in activity raises concerns for the weeks to come, i.e., the risk of a "second wave" of patients with 
decompensated chronic pathologies.

\section{Suggestions}

Public awareness campaigns are urgently needed to reassure the public of the safety of presenting for care. The public health community should proactively be involved in directing efforts at the political level to disseminate nuanced messages so that COVID-19 should not defer patients' seeking timely care for other conditions that may be fatal. Communication from healthcare professionals and public health officers is necessary to reinforce the importance of timely ED visits for acute health conditions in order to manage this observed hesitation to admit to the ED. Additionally, emergency departments must be reorganized with essential measures inspired by the principles of disaster medicine in order to face any unprecedented future health crises in light of the experiences of the COVID-19 pandemic.

\section{Limitations}

There are several limitations to our study. First, our study is limited by a relatively short timeframe, as we only included the data in the initial phase of the pandemic. It is possible that emergency help-seeking patterns could change as the pandemic progresses. Second, potential confounders related to patients' presentations in the ED including comorbidities and disease severity were not taken into account. Third, diagnoses were defined using the ICD-10 codes. Emergency medicine specialists may have entered different codes and slightly different pre-diagnoses may have existed; however, we assumed that dramatic differences in the coding of life-threatening conditions were unlikely. Fourth, we used hospital-based data, thus the study was limited to electronic records. Therefore, we could not check the patients' final diagnoses and their need for primary percutaneous transluminal coronary angioplasty (PTCA) by scanning and cross-checking separate patient files. Fifth, we did not monitor the entire processes within the hospital following the patients' admissions. Finally, hospital records could not provide the data on the temporal gap between the onset of symptoms and the arrival at the hospital. Similarly, there were no data on the polymerase chain reaction (PCR) outcomes of those who had been pre-diagnosed with COVID19.

\section{AUTHOR CONTRIBUTIONS}

YY and BE involved in all steps of the research such as the design, supervision, data collection, analysis, literature review, writing; while SY involved in the design, supervision, data collection, analysis, writing; EC worked on data processing.

\section{ETHICS APPROVAL AND CONSENT TO PARTICIPATE}

This research has received ethical approval from ATADEK on 14.01.2021 (Decree No.2021-01/17).

\section{ACKNOWLEDGMENT}

Thanks to all the peer reviewers for their opinions and suggestions.

\section{FUNDING}

This research received no external funding.

\section{CONFLICT OF INTEREST}

The authors declare no conflict of interest.

\section{REFERENCES}

[1] World Health Organization. Coronavirus disease (COVID-19). 2020. Available at: https://www.who.int/emergencies/diseases/ novel-coronavirus-2019/question-and-answers-hub/q-adetail/coronavirus-disease-covid-19 (Accessed: 12 October 2020).

[2] Centers for Disease Control and Prevention. COVID-19 overview and infection prevention and control priorities in non-US healthcare settings. 2020. Available at: https://www.cdc.gov/coronavirus/2019ncov/hcp/non-us-settings/overview/index.html (Accessed: 12 August 2020).

[3] Nicholls M. COVID-19 and cardiovascular disease. European Heart Journal. 2020; 41: 2727-2729.

[4] Rosenbaum L. The untold toll - the pandemic's effects on patients without Covid-19. New England Journal of Medicine. 2020; 382: 23682371.

[5] Kansagra AP, Goyal MS, Hamilton S, Albers GW. Collateral effect of Covid-19 on stroke evaluation in the United States. New England Journal of Medicine. 2020; 383: 400-401.

[6] Garcia S, Albaghdadi MS, Meraj PM, Schmidt C, Garberich R, Jaffer FA, et al. Reduction in ST-segment elevation cardiac catheterization laboratory activations in the United States during COVID-19 pandemic. Journal of the American College of Cardiology. 2020; 75: 2871-2872.

[7] Blecker S, Jones SA, Petrilli CM, Admon AJ, Weerahandi H, Francois F, et al. Hospitalizations for chronic disease and acute conditions in the time of COVID-19. JAMA Internal Medicine. 2021; 181: 269-271.

[8] Baum A, Schwartz MD. Admissions to veterans affairs hospitals for emergency conditions during the COVID-19 pandemic. Journal of the American Medical Association. 2020; 324: 96-99.

[9] Nourazari S, Davis SR, Granovsky R, Austin R, Straff DJ, Joseph JW, et al. Decreased hospital admissions through emergency departments during the COVID-19 pandemic. The American Journal of Emergency Medicine. 2021; 42: 203-210.

[10] Wongtanasarasin W, Srisawang T, Yothiya W, Phinyo P. Impact of national lockdown towards emergency department visits and admission rates during the COVID-19 pandemic in Thailand: a hospital-based study. Emergency Medicine Australasia. 2021; 33: 316-323.

[11] Atlas Journal. The chronology of COVID-19 pandemic. 2020. Available at: https://www.atlasdergisi.com/gundem/covid19-salgini-kronolojisi.html (Accessed: 4 December 2020).

[12] Metzler B, Siostrzonek P, Binder RK, Bauer A, Reinstadler SJ. Decline of acute coronary syndrome admissions in Austria since the outbreak of COVID-19: the pandemic response causes cardiac collateral damage. European Heart Journal. 2020; 41: 1852-1853.

[13] Rodríguez-Leor O, Cid-Álvarez B, Ojeda S, Martín-Moreiras J, Ramón Rumoroso J, López-Palop R, et al. Impacto de la pandemia de COVID-19 sobre la actividad asistencial en cardiología intervencionista en España. REC: Interventional Cardiology. 2020; 2: 82-89. (In Spanish)

[14] Hammad TA, Parikh M, Tashtish N, Lowry CM, Gorbey D, Forouzandeh $\mathrm{F}$, et al. Impact of COVID-19 pandemic on ST-elevation myocardial infarction in a non-COVID-19 epicenter. Catheterization and Cardiovascular Interventions. 2021; 97: 208-214.

[15] Krumholz HM. Where have all the heart attacks gone? The New York 
Times. 2020. Available at: https://www.nytimes.com/2020/04/ 06/well/live/coronavirus-doctors-hospitals-emergencycare-heart-attack-stroke.html (Accessed: 3 December 2020).

[16] Solomon MD, McNulty EJ, Rana JS, Leong TK, Lee C, Sung S, et al. The Covid-19 pandemic and the incidence of acute myocardial infarction. New England Journal of Medicine. 2020; 383: 691-693.

[17] Wong LE, Hawkins JE, Langness S, Murrell KL, Iris P, Sammann A. Where are all the patients? Addressing Covid-19 fear to encourage sick patients to seek emergency care. NEJM Catalyst. 2020.

[18] Ageron FX, Sarasin F, Pasquier M, Carron PN. Urgences hospitalières: crise COVID-19 et aspects organisationnels. Revue Medicale Suisse. 2020; 16: 924-929. (In French)

[19] Mafham MM, Spata E, Goldacre R, Gair D, Curnow P, Bray M, et al. COVID-19 pandemic and admission rates for and management of acute coronary syndromes in England. The Lancet. 2020; 396: 381-389.

[20] De Rosa S, Spaccarotella C, Basso C, Calabrò MP, Curcio A, Filardi PP, et al. Società Italiana di Cardiologia, \& CCU Academy investigators group. Reduction of hospitalizations for myocardial infarction in Italy in the COVID-19 era. European Heart Journal. 2020; 41: 2083-2088.

[21] Bhambhvani HP, Rodrigues AJ, Yu JS, Carr JB, Hayden Gephart M. Hospital volumes of 5 medical emergencies in the COVID-19 pandemic in 2 US medical centers. JAMA Internal Medicine. 2021; 181: 272-274.

[22] Daoulah A, Hersi AS, Al-Faifi SM, Alasmari A, Aljohar A, Balghith M, et al. STEMI and COVID-19 pandemic in Saudi Arabia. Current Problems in Cardiology. 2020; 46: 100656.

[23] Kuitunen I, Ponkilainen VT, Launonen AP, Reito A, Hevonkorpi TP, Paloneva $\mathrm{J}$, et al. The effect of national lockdown due to COVID19 on emergency department visits. Scandinavian Journal of Trauma, Resuscitation and Emergency Medicine. 2020; 28: 114.

[24] Griffin S. Covid-19: "Huge rise" in deaths at home is not fully explained by virus, say experts. British Medical Journal. 2020; 369: m2115.

[25] Wu J, Mamas MA, Mohamed MO, Kwok CS, Roebuck C, Humberstone $\mathrm{B}$, et al. Place and causes of acute cardiovascular mortality during the COVID-19 pandemic. Heart. 2020; 107: 113-119.

How to cite this article: Yeşim Yasin, Serpil Yaylacı, Berna Eren, Erdal Coşgun. An assessment of emergency department visits for cardiovascular diseases in the early phase of the COVID-19 pandemic in Istanbul. Signa Vitae. 2021;17(6):103111. doi:10.22514/sv.2021.100. 